\title{
Association of social worker-assessed psychosocial factors with 30-day hospital readmissions among hemodialysis patients
}

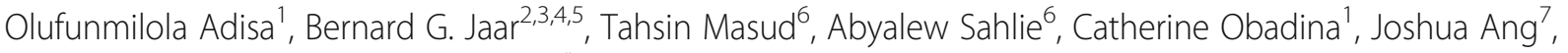
Janice P. Lea ${ }^{6}$ and Laura C. Plantinga ${ }^{1,6^{*}}$ (D)

\begin{abstract}
Background: Evidence regarding the effect of psychosocial factors on hospital readmission in the setting of hemodialysis is limited. We examined whether social worker-assessed factors were associated with 30-day readmission among prevalent hemodialysis patients.

Methods: Data on 14 factors were extracted from the first available psychosocial assessment performed by social workers at three metropolitan Atlanta dialysis centers. Index admissions (first admission preceded by $\geq 30$ days without a previous hospital discharge) were identified in the period 2/1/10-12/31/14, using linked national administrative hospitalization data. Readmission was defined as any admission within 30 days after index discharge. Associations of each of the psychosocial factors with readmission were assessed using multivariable logistic regression with adjustment for patient and index admission characteristics.

Results: Among 719 patients with index admissions, 22.1\% were readmitted within 30 days. No psychosocial factors were statistically significantly associated with readmission risk. However, history of substance abuse vs. none was associated with a $29 \%$ higher risk of 30-day readmission [OR: 1.29, 95\% Cl: 0.75-2.23], whereas depression/anxiety was associated with 20\% lower risk [OR: 0.80, 95\% Cl: 0.47-1.36]. Patients who were never married and those who were divorced, or widowed had 38 and 17\% higher risk of 30-day readmission, respectively, than those who were married [OR: 1.38, 95\% Cl: 0.84-2.72; OR: 1.17, 95\% Cl: 0.73-1.90].

Conclusions: Results suggest that psychosocial issues may be associated with risk of 30-day readmission among dialysis patients. Despite the limitations of lack of generalizability and potential misclassification due to patient self-report of psychosocial factors to social workers, further study is warranted to determine whether addressing these factors through targeted interventions could potentially reduce readmissions among hemodialysis patients.
\end{abstract}

Keywords: Hemodialysis, Hospital readmissions, Psychosocial factors, Mental health, Social worker

\section{Background}

In 2016, the Centers for Medicare \& Medicaid Services (CMS) spent $\$ 28$ billion on hemodialysis in the United States; about one-third of end-stage renal disease (ESRD) expenditures were for inpatient care [1]. As part of its ESRD Quality Incentive Program, CMS ties reimbursement of U.S. ESRD services to clinical performance [2].

\footnotetext{
* Correspondence: laura.plantinga@emory.edu

'Department of Epidemiology, Rollins School of Public Health, Emory University, Atlanta, GA, USA

${ }^{6}$ Division of Renal Medicine, Department of Medicine, Emory University,

Atlanta, GA, USA

Full list of author information is available at the end of the article
}

In 2017, this pay-for-performance program, added the standardized readmission ratio (SRR), such that facilities' Five-Star ratings may be reduced due to higher-than-expected hospital readmissions among their hemodialysis patient population. One of the major criticisms of the SRR is that, while it accounts for some demographic and clinical factors, it does not account for differences in psychosocial factors across facilities, which may disadvantage facilities with disproportionately vulnerable populations [3].

Despite this, relatively little is known about the effect of psychosocial factors on readmissions among hemodialysis patients. In a recent single-center study, El-Majzoub et al.

(C) The Author(s). 2018 Open Access This article is distributed under the terms of the Creative Commons Attribution 4.0 International License (http://creativecommons.org/licenses/by/4.0/), which permits unrestricted use, distribution, and 
[4] found that psychosocial distress was associated with shorter time to hospitalization, but did not examine hospital readmissions specifically. Flythe et al. [5] found that poor social support and depressive symptoms were associated with higher risk of hospital readmissions among dialysis patients in a prospective study. Both studies used validated tools that were administered in a study setting. However, it is possible that data collected routinely by social workers as part of usual hemodialysis care could capture a wide variety of psychosocial factors and potentially inform providers of patient risk of subsequent hospital readmission without the need for additional assessments. Thus, we aimed to use clinically available psychosocial information addressing a variety of domains, extracted from both structured and unstructured electronic medical record (EMR) data from three metropolitan Atlanta dialysis centers, to identify social worker-assessed psychosocial factors associated with risk of 30-day readmission among dialysis patients.

\section{Methods}

\section{Study design and population}

Data for this study were obtained from the EMR used by the three clinics operated by Emory Dialysis and from linked United States Renal Data System (USRDS) data [1]. The study was approved (with waiver of patient consent) by the Emory Institutional Review Board. We identified 1004 index hospitalizations in the period from 2/1/ 10 to $12 / 31 / 14$, using the linked USRDS hospitalization file. Patients were excluded if they had no hospitalizations preceded by $\geq 30$ days with a previous discharge $(n=65)$, if they did not have a baseline social worker assessment $(n=180)$, or died < 30 days from the index discharge $(n=40)$, leaving a study population of 719 index admissions (Fig. 1). For psychosocial variables, we extracted data from the first available social worker assessment for each patient. For analysis of individual psychosocial factors, index admissions were further excluded for missing data for that factor $(n=33-206)$, resulting analytic population sizes of 513-688 (Fig. 1).

\section{Study variables \\ Readmission}

Readmission was defined as any admission within 30 days after discharge from the index admission. Index admission was defined as the first admission that was preceded by $\geq 30$ days without a previous hospital discharge, to mitigate influence of frequently readmitted patients. Admission information was obtained from linked hospitalization data. Pulmonary edema-related readmissions were defined via discharge diagnoses International Classification of Diseases, Ninth Revision (ICD-9) codes of fluid overload (276.6, 276.61, or 276.69), heart failure (428.x, 402.× 1, 404.× 1, 404.×3, or 398.91), or pulmonary edema (518.4 or 514), in any position $[6,7]$.

\section{Psychosocial factors}

Assessments were performed using a form common to all social workers in all three facilities. The assessment items associated with the variables reported here can be found in Table 1. Psychosocial factors were categorized into four domains:

Mental health domain The history of substance abuse was defined by patient report and information about substance abuse from prior medical information accessible to the social worker. Depression or anxiety was defined as social worker-assessed presence of symptoms or signs of depression or anxiety at the time of assessment.

Social support domain Marital status was defined by the patient report, and categorized as domestic partner/ married, never married, and divorced/widowed/separated. Living alone was defined as not living with any other individual, including parents, children, other family, or friends. Frequency of social support from family and/or friends was dichotomized as daily vs. less than daily.

Independence domain Memory status was defined based on the social worker's observation of long-term or short-term memory impairment, which were combined as any vs. no memory impairment. Current employment was categorized as employed, disabled, and unemployed. The type of housing was dichotomized as communitydwelling vs. assisted living/nursing home. Mobility impairment was defined as "yes" to patient using an assistive device vs. none.

Ease of adherence domain Patient ease with coming to dialysis sessions, completing dialysis sessions, taking medications, adhering to dietary restrictions, and adhering to fluid restrictions were reported to the social worker. Responses were dichotomized as difficult ("somewhat difficult" or "very difficult," or "neither easy nor difficult") vs. easy ("somewhat easy" or "very easy").

\section{Other variables}

Patient age and duration of ESRD at index admission, sex, race, and index admission characteristics [length of stay and intensive care utilization ( $\geq 1$ day in an intensive care or coronary care unit during the index admission)] were obtained from USRDS. Comorbid conditions were assigned if they appeared on the CMS-2728 Medical Evidence form or were present in discharge codes from all hospital discharges in the year up to and including the index admission, using the diagnostic codes outlined in 


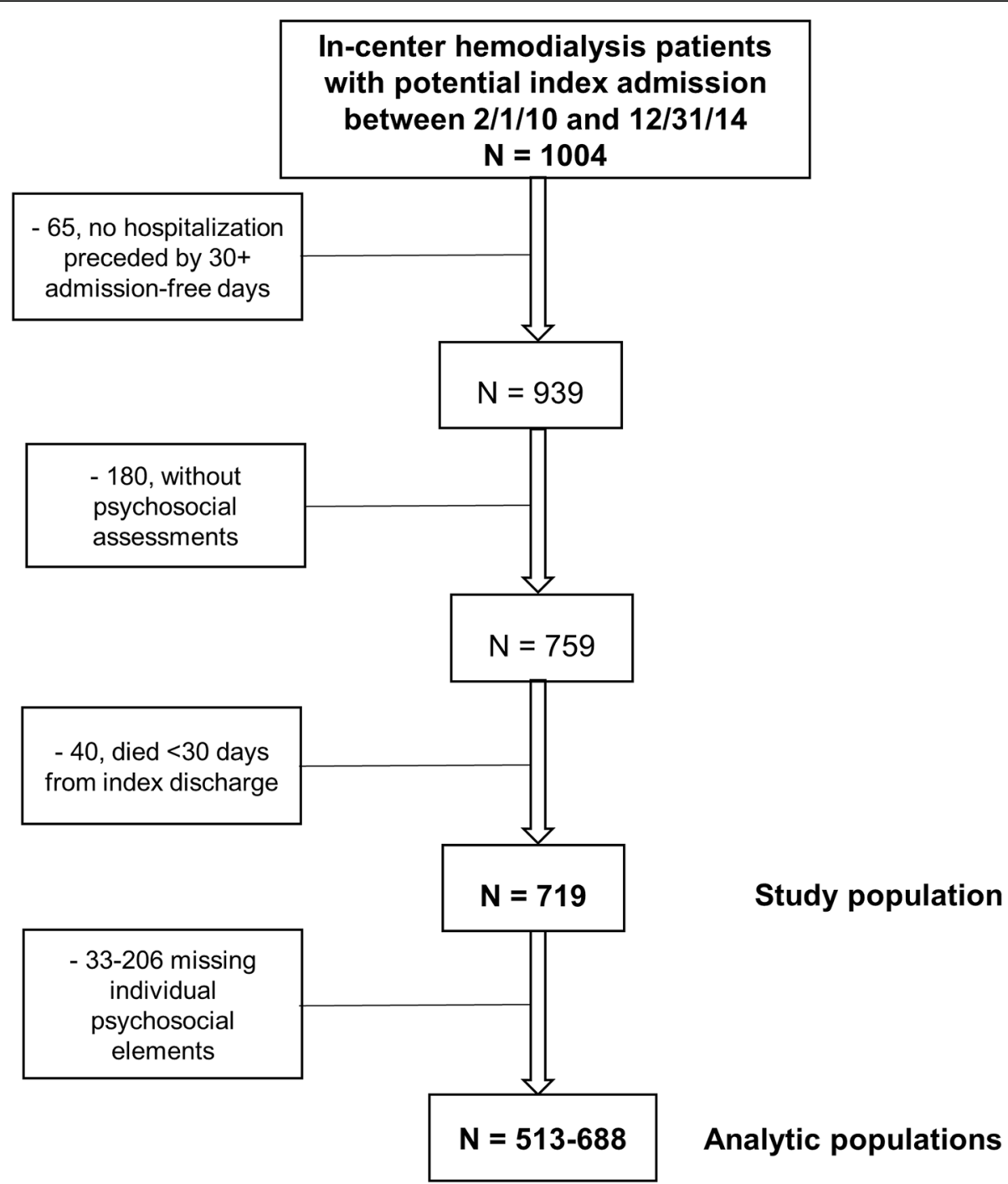

Fig. 1 Selection of patient population

the CMS Chronic Conditions Warehouse algorithms [8]. The assigned cause of ESRD and insurance type were recorded at the start of dialysis on the CMS-2728.

\section{Statistical analysis}

Patient and index admission characteristics were summarized. The burden of readmissions was determined as the percentage of index admissions that resulted in a readmission within 30 days of discharge from the index admission. Associations of each of the psychosocial factors with readmission [odds ratios (ORs)] were assessed using multivariable logistic regression analyses with and without adjustment for potential confounders. Additional adjustment for insurance type and for time between psychosocial assessment and index admission was performed in sensitivity analyses. In secondary analyses examining whether psychosocial factors might differentially affect readmissions for pulmonary edema (fluid overload) vs. other causes, we used multinomial logistic regression models to estimate adjusted ORs. SAS v. 10.4 (Cary, NC) and Stata v. 14.2 (College Station, TX) were used for analysis.

\section{Results}

\section{Patient characteristics}

The mean age of our predominantly black (91.8\%) study population was 56 ; more than half $(52.6 \%)$ were male (Table 2). Comorbid conditions were common, particularly hypertension, diabetes, congestive heart failure, and atherosclerotic cardiovascular disease. The median length of stay for the index admission was 4 days, and $21.7 \%$ were admitted to the ICU during the index admission. The median time between psychosocial assessment and index admission was 171 days. Overall, $22.1 \%$ of index admissions were followed by a 30-day readmission. Index admissions 
Table 1 Items from social worker assessments used to define psychosocial factors

\begin{tabular}{|c|c|c|}
\hline $\begin{array}{l}\text { Psychosocial } \\
\text { factors }\end{array}$ & Question/item & Possible responses \\
\hline \multicolumn{3}{|c|}{ Mental health domain } \\
\hline $\begin{array}{l}\text { History of } \\
\text { substance } \\
\text { abuse }\end{array}$ & $\begin{array}{l}\text { Has the patient ever had } \\
\text { a history of substance abuse? }\end{array}$ & $\begin{array}{l}\text { - No } \\
\text { - Yes }\end{array}$ \\
\hline $\begin{array}{l}\text { Depression } \\
\text { or anxiety }\end{array}$ & $\begin{array}{l}\text { Are there signs/symptoms } \\
\text { present for depression } \\
\text { or anxiety problems? }\end{array}$ & $\begin{array}{l}\text { - No } \\
\text { - Yes }\end{array}$ \\
\hline \multicolumn{3}{|c|}{ Social support domain } \\
\hline $\begin{array}{l}\text { Relationship } \\
\text { status }\end{array}$ & $\begin{array}{l}\text { What is the patient's } \\
\text { relationship status? }\end{array}$ & $\begin{array}{l}\text { - Domestic } \\
\text { partner } \\
\text { - Married } \\
\text { - Divorced } \\
\text { - Single } \\
\text { - Widowed } \\
\text { - Separated }\end{array}$ \\
\hline Living alone & $\begin{array}{l}\text { With whom does the } \\
\text { patient live? }\end{array}$ & $\begin{array}{l}\text { - Lives alone } \\
\text { - Lives with } \\
\text { parents } \\
\text { - Spouse } \\
\text { - Children } \\
\text { - Significant other } \\
\text { - Friend } \\
\text { - Relative } \\
\text { - Other }\end{array}$ \\
\hline $\begin{array}{l}\text { Frequency of } \\
\text { social support }\end{array}$ & $\begin{array}{l}\text { What is the level of } \\
\text { involvement of family and } \\
\text { friend on a regular basis? }\end{array}$ & $\begin{array}{l}\text { - Daily } \\
\text { - Weekly } \\
\text { - Monthly } \\
\text { - Less frequently } \\
\text { than monthly }\end{array}$ \\
\hline
\end{tabular}

Independence domain

Impaired Does the patient appear to

memory have a problem with the following?

memory

- No

- Yes

Long term

memory

- No

- Yes

Current Current employment?

employment

Mobility

Ambulatory assistance?

impairment

full-time

- Employed

part-time

- Retired

- Medical leave of

absence

- Unemployed-by

choice

- Unemployed

disabled

- Unemployed-

looking for work

- Other

- None

- Cane/crutch
Table 1 Items from social worker assessments used to define psychosocial factors (Continued)

\begin{tabular}{|c|c|c|}
\hline $\begin{array}{l}\text { Psychosocial } \\
\text { factors }\end{array}$ & Question/item & Possible responses \\
\hline $\begin{array}{l}\text { Type of } \\
\text { housing }\end{array}$ & Living status? & $\begin{array}{l}\text { - Home } \\
\text { - Condo } \\
\text { - Mobile home } \\
\text { - Apartment } \\
\text { - Rents house } \\
\text { - Assisted living } \\
\text { - Homeless } \\
\text { - Public housing } \\
\text { shelter } \\
\text { - Long term care } \\
\text { facility(SNF) } \\
\text { - Acute } \\
\text { rehabilitation } \\
\text { center } \\
\text { - Correctional } \\
\text { facility } \\
\text { - Adult family } \\
\text { home } \\
\text { - Adult group } \\
\text { home }\end{array}$ \\
\hline
\end{tabular}

Ease of adherence domain

Coming to Over the past month, how • N/A

dialysis easy or difficult has it been - Very easy for you to come to each • • • Somewhat easy hemodialysis treatment? - Neither easy nor difficult

- Somewhat difficult

- Very difficult

Completing Over the past month, how dialysis easy or difficult has it been sessions for you to complete the full-prescribed hemodialysis treatment time?

- N/A

- Very easy

- Somewhat easy

- Neither easy nor difficult

- Somewhat difficult

- Very difficult

Taking Over the past month, how medications easy or difficult has it been for you to take medications as prescribed?

- N/A

- Very easy

- Somewhat easy

- Neither easy nor difficult

- Somewhat

difficult

- Very difficult

Adhering

Adhering

Over the past month, how

- N/A

to dietary

restrictions

or difficult has it been

- Very easy

for you to follow dietary restrictions? - Somewhat easy

- Neither easy nor difficult

- Somewhat

difficult

- Very difficult

to fluid

Over the past month, how

- N/A

- Walker or

- Manual

wheelchair

- Electric

wheelchair

- Limb prosthesis
- Very easy

- Somewhat easy

- Neither easy

nor difficult

- Somewhat

difficult
- Very difficult 
Table 2 Characteristics of prevalent metropolitan Atlanta hemodialysis patients with index admissions from 2010 to 2014

\begin{tabular}{|c|c|c|c|c|c|}
\hline Characteristic & $N$ & Overall & Readmitted $(n=159)$ & Not readmitted $(n=560)$ & $P^{*}$ \\
\hline \multicolumn{6}{|l|}{ Patient characteristics } \\
\hline Mean age (SD), years & 719 & $56.1(14.9)$ & $55.2(15.4)$ & $56.3(14.7)$ & 0.4 \\
\hline Male sex, $n(\%)$ & 719 & $378(52.6)$ & $78(49.1)$ & $300(53.6)$ & 0.3 \\
\hline Black race, $n(\%)$ & 718 & $659(91.8)$ & $147(92.5)$ & $512(91.6)$ & $>0.9$ \\
\hline Medical insurance at dialysis start, $n(\%)$ & 692 & & & & 0.5 \\
\hline Medicare & & $122(17.6)$ & $34(22.2)$ & $88(16.3)$ & \\
\hline Medicaid & & $165(23.8)$ & $36(23.5)$ & $129(23.9)$ & \\
\hline Private & & $170(24.6)$ & $34(22.2)$ & $136(25.2)$ & \\
\hline Other & & $63(9.1)$ & $14(9.2)$ & $49(9.1)$ & \\
\hline None & & $172(24.9)$ & $35(22.9)$ & $137(25.4)$ & \\
\hline Comorbid conditions, $n(\%)$ & 719 & & & & \\
\hline Congestive heart failure & & $244(33.4)$ & $64(40.3)$ & $180(32.1)$ & 0.06 \\
\hline Hypertension & & $701(97.5)$ & $155(97.5)$ & $546(97.5)$ & $>0.9$ \\
\hline Diabetes & & $349(48.5)$ & $79(49.7)$ & $270(48.2)$ & 0.7 \\
\hline Atherosclerotic cardiovascular disease & & $141(19.6)$ & $34(21.4)$ & $107(19.1)$ & 0.5 \\
\hline Cause of ESRD, $n(\%)$ & 712 & & & & 0.3 \\
\hline Hypertension & & $308(43.3)$ & $49(30.8)$ & $144(26.0)$ & \\
\hline Diabetes & & $193(27.1)$ & $69(43.4)$ & $239(43.2)$ & \\
\hline Glomerulonephritis & & $73(10.3)$ & $18(11.3)$ & $55(10.0)$ & \\
\hline Other & & $138(19.4)$ & $23(14.5)$ & $115(20.8)$ & \\
\hline Median duration of ESRD (IQR), years & 719 & $2.1(0.6-5.9)$ & $1.5(0.5-5.4)$ & $2.2(0.7-6.3)$ & 0.1 \\
\hline \multicolumn{6}{|l|}{ Index admission characteristics } \\
\hline Median length of stay (IQR), days & 719 & $4(2-6)$ & $4(2-8)$ & $3(2-6)$ & 0.007 \\
\hline Intensive care utilization, n (\%) & 719 & $156(21.7)$ & $42(26.4)$ & $114(20.4)$ & 0.1 \\
\hline
\end{tabular}

Characteristics are assessed at index admission unless otherwise noted. ESRD End-stage renal disease, IQR Interquartile range, SD Standard deviation *By chi-square, $t$, or rank-sum test, as appropriate

followed by a readmission vs. not were longer, but there were no other statistically significant differences in index admission or patient characteristics by readmission status (Table 2).

\section{Distributions of psychosocial factors}

Table 3 shows the distribution of psychosocial factors by domain. In general, low levels of substance abuse and depression/anxiety and high levels of social support were reported. While many required ambulatory assistance, most were reported to be fairly independent. Most patients reported ease of adherence to coming to and completing dialysis sessions, taking medications, and adhering to dietary and fluid restrictions. There were no statistically significant differences in distributions of these factors by readmitted status (Table 3 ).

\section{Association of Psychosocial Factors with 30-day readmissions}

No associations between psychosocial factors and 30-day readmissions were statistically significant, regardless of adjustment. However, Table 4 shows that some of the psychosocial factors examined were non-statistically significantly associated with 30-day readmission risk. For example, a history of substance abuse vs. none was non-statistically significantly associated with a $29 \%$ increased risk of 30-day readmission, whereas depression/anxiety at the time of assessment was nonstatistically significantly associated with $20 \%$ lower readmission risk. For those who were never married and those who were divorced, separated, or widowed, vs. married, risks of 30-day readmission were 38 and $17 \%$ higher, respectively, but associations were non-statistically significant. Other factors reflecting social support, including living alone and less frequent social support, had null associations with readmission risk (Table 3). Memory impairment, being disabled vs. unemployed, and using assistive devices for ambulation were nonstatistically significantly associated with 24,20 , and $25 \%$ lower readmission risk, respectively. Those who reported difficulty with coming to dialysis had $25 \%$ lower risk of 30-day readmission, whereas reported difficulties 
Table 3 Distributions of social worker-assessed baseline psychosocial factors among hemodialysis patients, by domain

\begin{tabular}{|c|c|c|c|c|c|}
\hline \multirow[t]{2}{*}{ Psychosocial domain/factor } & \multirow[t]{2}{*}{$N$} & \multicolumn{3}{|l|}{$n(\%)$} & \multirow[t]{2}{*}{$P^{*}$} \\
\hline & & Overall & Readmitted & Not readmitted & \\
\hline \multicolumn{6}{|l|}{ Mental health } \\
\hline History of substance abuse, yes vs. no & 680 & $90(13.2)$ & $22(15.0)$ & $68(12.8)$ & 0.3 \\
\hline Depression or anxiety, yes vs.no & 666 & $114(17.1)$ & $21(14.5)$ & $93(17.9)$ & 0.5 \\
\hline \multicolumn{6}{|l|}{ Social support } \\
\hline Marital Status & 686 & & & & 0.3 \\
\hline Never married & & $239(34.8)$ & $40(26.5)$ & $173(32.3)$ & \\
\hline Married/ domestic partner & & $213(31.1)$ & $59(39.1)$ & 180 (33.6) & \\
\hline Divorced/separated/widowed & & $234(34.1)$ & $52(34.4)$ & $182(34.0)$ & \\
\hline Living alone & 688 & $150(21.8)$ & $34(22.7)$ & $116(21.6)$ & 0.8 \\
\hline Daily social support & 673 & $469(69.7)$ & $100(67.6)$ & $369(70.3)$ & 0.5 \\
\hline \multicolumn{6}{|l|}{ Independence } \\
\hline Impaired memory & 678 & $106(15.6)$ & $19(13.1)$ & $87(16.3)$ & 0.3 \\
\hline Employment at assessment & 542 & & & & 0.4 \\
\hline Employed & & $43(7.9)$ & $--_{-}^{* *}$ & $37(8.7)$ & \\
\hline Disabled & & $314(57.9)$ & $67(57.8)$ & $247(58.0)$ & \\
\hline Unemployed & & $185(34.1)$ & $43(37.1)$ & $142(33.3)$ & \\
\hline Community-dwelling & 678 & $623(91.9)$ & $135(91.2)$ & $488(92.1)$ & 0.7 \\
\hline Requires ambulatory assistance & 683 & $278(40.7)$ & $55(37.4)$ & $223(41.6)$ & 0.4 \\
\hline \multicolumn{6}{|l|}{ Ease of adherence } \\
\hline Easy to come to dialysis & 517 & $397(76.8)$ & $92(80.7)$ & $305(75.7)$ & 0.3 \\
\hline Easy to complete dialysis & 513 & $387(75.4)$ & $85(75.9)$ & $302(75.3)$ & 0.9 \\
\hline Easy to take medications & 527 & $441(83.7)$ & $98(83.1)$ & $343(83.9)$ & 0.8 \\
\hline Easy to adhere to dietary restrictions & 523 & $332(63.5)$ & $69(60.0)$ & $263(64.5)$ & 0.3 \\
\hline Easy to adhere to fluid restrictions & 519 & $358(69.0)$ & $75(65.2)$ & $283(70.1)$ & 0.3 \\
\hline
\end{tabular}

*By chi-square test. **Suppressed due to insufficient sample size $(n<10)$

with adhering to dietary and fluid recommendations were associated with 20 and $22 \%$ higher risk, respectively, compared to reported ease of adherence, but associations were again non-statistically significant. Additional adjustment for insurance type at dialysis start and for time between psychosocial assessment and index admission did not change results substantially (data not shown).

In secondary analyses (Table 5), there were differences in the associations of pulmonary edema-related (31.5\%) and other (68.5\%) vs. no readmissions and several psychosocial factors. For example, living in assisted living or a nursing home vs. in the community was associated with 2.5 -fold higher risk of pulmonary edemarelated vs. no readmission, but $40 \%$ lower risk of other vs. no readmission. Difficulty adhering to fluid restrictions was associated with $67 \%$ higher risk of pulmonary edema-related readmissions only, and history of substance abuse was associated with $30 \%$ higher risk of other vs. no readmission only. Associations between the outcome and depression/anxiety, marital status, and frequency of social support, were similar for the two types of readmission vs. no readmission (Table 5).

\section{Discussion}

We found that $22.1 \%$ of index admissions were followed by a readmission, similar to recent national studies using similar methodology [9]. Importantly, in this study examining social worker assessment-derived psychosocial factors and 30-day readmission risk among prevalent hemodialysis patients, associations were not statistically significant. However, our results do suggest that history of substance abuse, being unmarried, and patient-reported difficulty adhering to dietary and fluid restrictions may be associated with higher readmission risk, independent of patient and index admission factors. In contrast, depression/anxiety, impaired memory, requiring ambulatory assistance, being workdisabled or employed vs. unemployed, and patient-reported difficulty coming to dialysis were associated with lower readmission risk in our analyses. The other 
Table 4 Association of social worker-assessed psychosocial factors with hospital readmissions among prevalent hemodialysis patients, 2010-2014

\begin{tabular}{|c|c|c|c|}
\hline \multirow[t]{2}{*}{ Psychosocial domain/factor } & \multirow{2}{*}{$\begin{array}{l}\text { No. (\%) } \\
\text { readmitted } \\
\text { within } 30 \text { days }\end{array}$} & \multicolumn{2}{|c|}{ OR $(95 \% \mathrm{Cl})$ for readmission } \\
\hline & & Unadjusted & Adjusted* \\
\hline \multicolumn{4}{|l|}{ Mental health } \\
\hline \multicolumn{4}{|l|}{ History of substance abuse } \\
\hline Overall & $147 / 680(21.6 \%)$ & - & - \\
\hline No & $125 / 590(21.2 \%)$ & 1.00 (referent) & 1.00 (referent) \\
\hline Yes & $22 / 90(24.4 \%)$ & $1.20(0.72-2.02)$ & $1.29(0.75-2.23)$ \\
\hline \multicolumn{4}{|l|}{ Depression or anxiety } \\
\hline Overall & $145 / 666(21.8 \%)$ & - & - \\
\hline No & $124 / 552(22.5 \%)$ & 1.00 (referent) & 1.00 (referent) \\
\hline Yes & $21 / 114(18.4 \%)$ & $0.78(0.47-1.30)$ & $0.80(0.47-1.36)$ \\
\hline \multicolumn{4}{|l|}{ Social support } \\
\hline \multicolumn{4}{|l|}{ Marital status } \\
\hline Overall & 151/686 (22.0\%) & - & - \\
\hline Married/domestic partner & $40 / 213(18.8 \%)$ & 1.00 (referent) & 1.00 (referent) \\
\hline Never married & $59 / 239(24.7 \%)$ & $1.42(0.90-2.23)$ & $1.38(0.84-2.27)$ \\
\hline Widowed/divorced/separated & $52 / 234(22.2 \%)$ & $1.24(0.79-1.96)$ & $1.17(0.73-1.90)$ \\
\hline \multicolumn{4}{|l|}{ Lives alone } \\
\hline Overall & 150/688 (21.8\%) & - & - \\
\hline No & $116 / 538(21.6 \%)$ & 1.00 (referent) & 1.00 (referent) \\
\hline Yes & $34 / 150(22.7 \%)$ & $1.07(0.69-1.65)$ & $1.16(0.74-1.81)$ \\
\hline \multicolumn{4}{|l|}{ Frequency of social support } \\
\hline Overall & 148/673 (22.0\%) & - & - \\
\hline Daily & 100/469 (21.3\%) & 1.00 (referent) & 1.00 (referent) \\
\hline Not daily & $48 / 204(23.5 \%)$ & $1.14(0.77-1.68)$ & $1.14(0.76-1.70)$ \\
\hline \multicolumn{4}{|l|}{ Independence } \\
\hline \multicolumn{4}{|l|}{ Impaired memory } \\
\hline Overall & 145/678 (21.4\%) & - & - \\
\hline No & 126/572 (22.0\%) & 1.00 (referent) & 1.00 (referent) \\
\hline Yes & 19/106 (17.9\%) & $0.77(0.45-1.32)$ & $0.76(0.44-1.32)$ \\
\hline \multicolumn{4}{|l|}{ Employment status } \\
\hline Overall & 116/542 (21.4\%) & - & - \\
\hline Unemployed & $43 / 185(23.2 \%)$ & 1.00 (referent) & 1.00 (referent) \\
\hline Disabled & $67 / 314(21.3 \%)$ & $0.90(0.58-1.38)$ & $0.80(0.49-1.32)$ \\
\hline Employed & $6 / 43(14.0 \%)$ & $0.54(0.21-1.35)$ & $0.54(0.20-1.45)$ \\
\hline \multicolumn{4}{|l|}{ Type of Housing } \\
\hline Overall & 148/678 (21.8\%) & - & - \\
\hline Community-dwelling & $135 / 623(21.7 \%)$ & 1.00 (referent) & 1.00 (referent) \\
\hline Assisted living/nursing home & 13/55 (23.6\%) & $1.12(0.58-2.14)$ & $1.07(0.52-2.17)$ \\
\hline \multicolumn{4}{|l|}{ Ambulatory assistance } \\
\hline Overall & 147/683 (21.8\%) & - & - \\
\hline No & $92 / 405(22.7 \%)$ & 1.00 (referent) & 1.00 (referent) \\
\hline Yes & $55 / 278(19.8 \%)$ & $0.84(0.58-1.22)$ & $0.75(0.48-1.16)$ \\
\hline
\end{tabular}

Ease of adherence 
Table 4 Association of social worker-assessed psychosocial factors with hospital readmissions among prevalent hemodialysis patients, 2010-2014 (Continued)

\begin{tabular}{|c|c|c|c|}
\hline \multirow[t]{2}{*}{ Psychosocial domain/factor } & \multirow{2}{*}{$\begin{array}{l}\text { No. }(\%) \\
\text { readmitted } \\
\text { within } 30 \text { days }\end{array}$} & \multicolumn{2}{|c|}{ OR $(95 \% \mathrm{Cl})$ for readmission } \\
\hline & & Unadjusted & Adjusted* \\
\hline \multicolumn{4}{|l|}{ Coming to dialysis } \\
\hline Overall & $114 / 517(22.1 \%)$ & - & - \\
\hline Easy & 92/397 (23.2\%) & 1.00 (referent) & 1.00 (referent) \\
\hline Difficult & $22 / 120(18.3 \%)$ & $0.74(0.44-1.25)$ & $0.75(0.44-1.27)$ \\
\hline \multicolumn{4}{|l|}{ Completing dialysis } \\
\hline Overall & $112 / 513(21.8 \%)$ & - & - \\
\hline Easy & 85/387 (22.0\%) & 1.00 (referent) & 1.00 (referent) \\
\hline Difficult & $27 / 126(21.4 \%)$ & $0.97(0.59-1.58)$ & $0.98(0.59-1.62)$ \\
\hline \multicolumn{4}{|l|}{ Taking medications } \\
\hline Overall & 118/527 (22.4\%) & - & - \\
\hline Easy & $98 / 441(22.2 \%)$ & 1.00 (referent) & 1.00 (referent) \\
\hline Difficult & 20/86 (23.3\%) & $1.06(0.61-1.84)$ & $1.04(0.59-1.82)$ \\
\hline \multicolumn{4}{|l|}{ Adhering to diet restrictions } \\
\hline Overall & 115/523 (22.0\%) & - & - \\
\hline Easy & 69/332 (20.8\%) & 1.00 (referent) & 1.00 (referent) \\
\hline Difficult & 46/191 (24.1\%) & $1.21(0.79-1.85)$ & $1.20(0.78-1.85)$ \\
\hline \multicolumn{4}{|c|}{ Adhering to fluid restrictions } \\
\hline Overall & $115 / 519(22.2 \%)$ & - & - \\
\hline Easy & 75/358 (21.0\%) & 1.00 (referent) & 1.00 (referent) \\
\hline Difficult & 40/161 (24.8\%) & $1.25(0.80-1.93)$ & $1.22(0.78-1.92)$ \\
\hline
\end{tabular}

*Adjusted for age, sex, race, duration of ESRD, history of diabetes, congestive heart failure, and atherosclerotic diseases, index admission length of stay, and intensive care utilization during index admission

factors we examined-living alone, less frequent social support, community-dwelling vs. assisted living/nursing home, reported difficulty with completing dialysis sessions and taking medications-were not associated with readmission risk overall. However, analyses with a stratified outcome (pulmonary edema-related and other readmissions vs. no readmissions) suggested that living in assisted living or a nursing home and difficulty adhering to fluid restrictions or completing dialysis were associated with increased risk of pulmonary edema-related readmissions, while living alone was associated with increased risk of other readmissions.

Unexpectedly, we found that signs and symptoms of depression/anxiety at start of treatment were associated with $20 \%$ lower readmission risk, in contrast to the > 2-fold higher risk of hospitalization [4] and readmission [5] associated with positive screening for depression reported among hemodialysis patients, and to the 1.7 -fold higher risk of readmission seen in hospitalized patients generally [10]. It is possible that patients thought by social workers to have depression/anxiety are followed more closely, resulting in lower readmission risk, or that these symptomatic patients are less likely to seek treatment, delaying readmissions past the 30-day threshold. However, this result could be partially attributable to differences in the timing of measurement between our study and these prior studies, if symptoms at discharge have more effect on readmission than chronic depression/anxiety. Social workers may also underdiagnosing depression and anxiety-which seems likely, given that about half of prevalent hemodialysis patients show signs of depression [11] and we found that only $17 \%$ of our population were noted to have depression at baseline. Since depression is associated with lower treatment adherence among dialysis patients [12, 13] and transplant recipients $[13,14]$, it may be important to assess depressive symptoms in this population more accurately and more frequently over time to determine readmission risk. Such work could lead to clinical interventions to reduce depressive symptoms including psychotherapy [15] and mindfulness meditation [16], which may effective in this population.

Non-married status was associated with higher risk of readmission, with no associations seen for frequency of social support or living alone. These results suggest that marital status may provide some protection beyond the 
Table 5 Association of social worker-assessed psychosocial factors with pulmonary edema-related and other hospital readmissions, vs. no readmissions, among prevalent hemodialysis patients, 2010-2014

\begin{tabular}{lll}
\hline Psychosocial & & \\
\cline { 2 - 2 } domain/factor & $\begin{array}{l}\text { Pulmonary edema-related } \\
\text { readmission vs. no readmission }\end{array}$ & $\begin{array}{l}\text { Other readmission } \\
\text { vs. no readmission }\end{array}$ \\
\hline Mental health & &
\end{tabular}

$$
\begin{array}{ll}
\text { History of substance abuse } \\
\text { No } & 1.00 \text { (referent) } \\
\text { Yes } & 1.00(0.41-2.45) \\
\text { Depression or anxiety } \\
\text { No } & 1.00 \text { (referent) }
\end{array}
$$

Frequency of social support

$\begin{array}{ll}\text { Overall } & - \\ \text { Daily } & 1.00 \text { (referent) }\end{array}$

\begin{tabular}{|c|c|}
\hline Overall & - \\
\hline Unemployed & 1.00 (referent) \\
\hline Disabled & $0.27(0.03-2.15)$ \\
\hline Employed & $0.90(0.45-1.82)$ \\
\hline \multicolumn{2}{|l|}{ ype of Housing } \\
\hline $\begin{array}{l}\text { Community- } \\
\text { dwelling }\end{array}$ & 1.00 (referent) \\
\hline $\begin{array}{l}\text { Assisted living/ } \\
\text { nursing home }\end{array}$ & $2.45(1.07-5.58)$ \\
\hline \multicolumn{2}{|c|}{ Ambulatory assistance } \\
\hline No & 1.00 (referent) \\
\hline Yes & $1.23(0.67-2.26)$ \\
\hline
\end{tabular}

Not daily $\quad 1.11(0.58-2.11)$

Independence

$\begin{array}{ll}\text { Impaired memory } & \\ \text { No } & 1.00 \text { (referent) } \\ \text { Yes } & 1.05 \text { (0.48-2.33) }\end{array}$

Employment status

$0.70(0.45-1.10)$

\begin{tabular}{|c|c|c|}
\hline \multirow{2}{*}{$\begin{array}{l}\text { Psychosocial } \\
\text { domain/factor }\end{array}$} & \multicolumn{2}{|l|}{ Unadjusted OR (95\% Cl) } \\
\hline & $\begin{array}{l}\text { Pulmonary edema-related } \\
\text { readmission vs. no readmission }\end{array}$ & $\begin{array}{l}\text { Other readmission } \\
\text { vs. no readmission }\end{array}$ \\
\hline \multicolumn{3}{|c|}{ Ease of adherence } \\
\hline \multicolumn{3}{|c|}{ Coming to dialysis } \\
\hline Easy & 1.00 (referent) & 1.00 (referent) \\
\hline Difficult & $1.00(0.46-2.19)$ & $0.63(0.33-1.20)$ \\
\hline \multicolumn{3}{|c|}{ Completing dialysis } \\
\hline Easy & 1.00 (referent) & 1.00 (referent) \\
\hline Difficult & $1.34(0.64-2.83)$ & $0.81(0.45-1.48)$ \\
\hline \multicolumn{3}{|c|}{ Taking medications } \\
\hline Easy & 1.00 (referent) & 1.00 (referent) \\
\hline Difficult & $1.17(0.50-2.78)$ & $1.01(0.53-1.93)$ \\
\hline \multicolumn{3}{|c|}{ Adhering to diet restrictions } \\
\hline Easy & 1.00 (referent) & 1.00 (referent) \\
\hline Difficult & $1.30(0.65-2.59)$ & $1.17(0.71-1.92)$ \\
\hline \multicolumn{3}{|c|}{ Adhering to fluid restrictions } \\
\hline Easy & 1.00 (referent) & 1.00 (referent) \\
\hline Difficult & $1.67(0.83-3.35)$ & $1.08(0.64-1.82)$ \\
\hline
\end{tabular}

Table 5 Association of social worker-assessed psychosocial factors with pulmonary edema-related and other hospital readmissions, vs. no readmissions, among prevalent hemodialysis patients, 2010-2014 (Continued)

presence of social support. However, it is also possible our measure of social support, which did not distinguish types [4] or providers of social support received, may not fully capture social support. Interestingly, several factors that indicate potential lack of independence in these hemodialysis patients, including impaired memory, requiring ambulatory assistance, and being work-disabled vs. unemployed were all associated with lower risk of readmission in our study. It is possible that such patients are followed more closely, both by dialysis providers and by caregivers, thus reducing the risk of readmission. Living in a nursing home or in assisted living, where patients are theoretically followed more closely than community-dwelling patients, did not provide this protection, but this discrepancy may be partially due to increased medical complexity of patients who are no longer community-dwelling. Furthermore, stratified outcomes suggested that, while those in assisted living/nursing homes were at lower risk of other readmissions, they were at higher risk of pulmonary edema-related readmissions. This may reflect a general protective effect of continuing medical care post-discharge, but poor post-discharge dialysis management among these patients. Because nursing homes are also now held accountable for readmissions [17], it may be important to explore better 
continuity of dialysis care specifically between nursing homes and dialysis facilities.

Difficulty with adherence was associated with both higher (dietary and fluid restrictions) and lower (coming to dialysis) risk of readmission. The prior association may reflect patient's assessment of self-management skills, which are needed to understand and execute discharge instructions, including medication management-although we found no association with reported difficulty taking medications and readmission risk. The latter may reflect provider knowledge of and attempts to circumvent barriers to coming to dialysis (e.g., lack of transportation) among these patients. However, reported difficulty completing dialysis was not associated with overall readmission risk. These inconsistencies may reflect different types of adherence in dialysis being associated with different factors: for example, depression has been associated with missed dialysis [18] and medication adherence [13], but financial difficulties and provider and health system factors are also associated with problems taking medications [19]. Of course, these somewhat unexpected patterns could also be partially attributable to the misclassification due to self-reported data: while patients may report adherence to be "easy," they may not find it to be easy in practice; furthermore, patients may not adhere to treatment recommendations for many reasons, related to trust, health literacy, polypharmacy, side effects, and financial barriers [20]. Culturally sensitive interventions to increase self-efficacy, individualized to patients' problems with adherence, may be needed and may help prevent some readmissions $[18,21,22]$.

There are several possible explanations for the lack of statistical significance in our results, including that psychosocial risk factors may not be associated with readmissions in the hemodialysis population. It is also possible that psychosocial factors do not contribute substantially to the ability of other demographic and clinical factors to predict readmissions. Flythe et al. [5] found that the associations between poor social support and depressive symptoms and higher risk of hospital readmissions among dialysis patients were independent of patient and index admission factors, making the explanation of a true null association less likely. Furthermore, in the general population, both patients [23] and providers [24] identify psychosocial variables as the primary reasons for readmissions, and it seems unlikely that these factors have no effect in the hemodialysis population. A future prospective study using validated instruments that are administered by social workers but standardized across multiple centers, or a retrospective study of a much larger dialysis organization (assuming standardized data collection by social workers), is needed to confirm these associations.
Other potential explanations for lack of statistical significance include inadequate statistical power, particularly in smaller subgroups; lack of an effect among our relatively homogeneous patient population, which is entirely urban and predominantly poor; potential selection bias due to missing data; and potential misclassification of the psychosocial factors. The potential for social desirability bias may be even stronger at the baseline assessment, since trust and rapport between social worker and hemodialysis patient may take time to establish [25]. Related to the timing of psychosocial assessment, misclassification is also possible due to the variable time lag between social worker assessment and index admission, which, on average, was around 6 months but was much longer for some patients. However, our results adjusting for this lag gave similar results.

Despite such limitations, our results do provide hypotheses that could be tested in future studies that inform clinical care and policy. Prior studies in the dialysis population have primarily focused on clinical risk factors for readmission [26-28], but the policy-driven nature of hemodialysis care has generated interest in other patient factors, including depression, social support, and health literacy [5], that could be modified to reduce readmission risk, or used for adjustment to make between-facility comparisons such as the dialysis SRR more fair. In our study, we leveraged existing social worker assessment data, which would be more readily available to policymakers, to examine the effects of multiple psychosocial factors addressing mental health, social support, independence, and ease of adherence on hospital readmission among hemodialysis patients.

There are additional limitations to this study that not already noted above. We excluded those patients with a recent previous hospitalization and those who died within 30 days from index discharge, which could lead to an underestimation of our outcome. Predictors of multiple readmissions or readmissions followed by death may differ from the predictors of the single readmission outcome examined here. While all social workers used the same form, there are no national standards for clinical collection of psychosocial information on patients and the assessment items on these clinical forms, including those for depression assessment, are not validated despite the availability of instruments for this population. Detailed information on medications used for depression/anxiety and on psychotherapy history was limited. Similarly, information on substance abuse did not include detailed information on duration or type of substance (e.g., intravenous vs. by mouth). However, strengths of the study include comprehensive evaluation of multiple psychosocial factors and linkage of data to administrative data with nearly complete capture of hospitalizations. 


\section{Conclusions}

This study adds to the body of knowledge on how psychosocial factors may affect 30-day readmission in hemodialysis patients. Our results could generate several hypotheses regarding psychosocial factors as potential predictors of readmission, potentially leading to future studies that inform polices and strategies to reduce readmissions among patients on hemodialysis. More frequent and robust collection of data on psychosocial factors, whether by the dialysis social worker or others, is needed. Such data may help guide targeted interventions to reduce readmissions, ultimately reducing costs and improving quality of life among hemodialysis patients.

\section{Abbreviations \\ CMS: Centers for Medicare \& Medicaid Services; EMR: Electronic medical record; ESRD: End-stage renal disease; OR: Odds ratio; SRR: Standardized readmissions ratio; USRDS: United States Renal Data System}

\section{Acknowledgements}

We thank the patients and staff of the Emory dialysis centers. We also thank Marshia Coe, Troy Walker, and Chad Robichaux for their assistance with the electronic medical record (EMR) data and Kevin Abbott for his assistance with the linked USRDS data. This work was presented in part at the annual meeting of AcademyHealth, held in Seattle, Washington, June 24-26, 2018. Some of the data reported here have been supplied by the USRDS. The interpretation and reporting of the USRDS data are the responsibility of the authors and in no way should be seen as an official policy or interpretation of the U.S. government.

\section{Funding}

This project was supported by grant number R03HS025018 from the Agency for Healthcare Research and Quality. The content is solely the responsibility of the authors and does not necessarily represent the official views of the Agency for Healthcare Research and Quality.

\section{Availability of data and materials}

USRDS data are available to investigators via request (https://www.usrds.org). The electronic medical record data presented here are proprietary and available to investigators upon reasonable request and with permission of Health Systems Management, Inc.

\section{Authors' contributions}

OA and LCP analyzed the data and drafted the manuscript. OA, AS, CO, JA, $J P L$, and LCP obtained the data. LP and BGJ obtained funding for the work. $\mathrm{TM}, J P L$, and BGJ provided clinical expertise in nephrology. All authors provided critical reviews of the manuscript and read and approved the final manuscript.

\section{Ethics approval and consent to participate}

Approval and oversight for this study was provided by the Emory Institutional Review Board (IRB00082448). Informed consent was waived for this secondary data analysis,

\section{Consent for publication}

Not applicable.

\section{Competing interests}

LP and BGJ serve on the Editorial Board of BMC Nephrology. The authors declare that they have no other competing interests.

\section{Publisher's Note}

Springer Nature remains neutral with regard to jurisdictional claims in published maps and institutional affiliations.

\section{Author details}

'Department of Epidemiology, Rollins School of Public Health, Emory University, Atlanta, GA, USA. ${ }^{2}$ Department of Medicine, Johns Hopkins School of Medicine, Baltimore, MD, USA. ${ }^{3}$ Welch Center for Prevention, Epidemiology and Clinical Research, Johns Hopkins University, Baltimore, MD, USA. ${ }^{4}$ Department of Epidemiology, Johns Hopkins Bloomberg School of Public Health, Baltimore, MD, USA. ${ }^{5}$ Nephrology Center of Maryland, Baltimore, MD, USA. ${ }^{6}$ Division of Renal Medicine, Department of Medicine, Emory University, Atlanta, GA, USA. ${ }^{7}$ Philadelphia College of Osteopathic Medicine, Suwanee, GA, USA.

Received: 18 October 2018 Accepted: 29 November 2018

Published online: 17 December 2018

\section{References}

1. United States Renal Data System. USRDS 2018 Annual Data Report: Atlas of Chronic Kidney Disease and End-Stage Renal Disease in the United States. Bethesda: National Institutes of Health, National Institute of Diabetes and Digestive and Kidney Diseases; 2018.

2. Centers for Medicare \& Medicaid Services. End-stage renal disease prospective payment system, quality incentive program, and durable medical equipment, prosthetics, orthotics, and supplies: final rule. Fed Register. 2014;79(215):66119-265.

3. Fishbane S, Wish JB. Quality measurement in wonderland: the curious case of a dialysis readmissions measure. Clin J Am Soc Nephrol. 2016;11 (1):190-4.

4. El-Majzoub S, Mucsi I, Li M, Moussaoui G, Lipman ML, Looper KJ, Novak M, Rej S. Psychosocial distress and health service utilization in patients undergoing hemodialysis: a prospective study. Psychosomatics. 2018: in press. https://www.ncbi.nlm.nih.gov/pubmed/30396686.

5. Flythe JE, Hilbert J, Kshirsagar A, Gilet CA. Psychosocial factors and 30-day hospital readmission among individuals receiving maintenance dialysis: a prospective study. Am J Nephrol. 2017;45(5):400-8.

6. Arneson TJ, Liu J, Qiu Y, Gilbertson DT, Foley RN, Collins AJ. Hospital treatment for fluid overload in the Medicare hemodialysis population. Clin J Am Soc Nephrol. 2010;5(6):1054-63.

7. Assimon MM, Nguyen T, Katsanos SL, Brunelli SM, Flythe JE. Identification of volume overload hospitalizations among hemodialysis patients using administrative claims: a validation study. BMC Nephrol. 2016;17(1):173.

8. Centers for Medicare \& Medicaid Services. Chronic Conditions Data Warehouse. 2018. Available at: https://www.ccwdata.org/web/guest/home

9. Chan $L$, Chauhan K, Poojary P, Saha A, Hammer E, Vassalotti JA, Jubelt $L$, Ferket B, Coca SG, Nadkarni GN. National estimates of 30-day unplanned readmissions of patients on maintenance hemodialysis. Clin J Am Soc Nephrol. 2017;12(10):1652-62.

10. Pederson JL, Warkentin LM, Majumdar SR, McAlister FA. Depressive symptoms are associated with higher rates of readmission or mortality after medical hospitalization: a systematic review and meta-analysis. J Hosp Med. 2016;11(5):373-80.

11. Cirillo L, Cutruzzula R, Somma C, Gregori M, Cestone G, Pizzarelli C, Toccafondi A, Pizarelli F, Dattolo PC. Depressive symptoms in dialysis: prevalence and relationship with uremia-related biochemical parameters. Blood Purif. 2018;46(4):286-91.

12. Washington TR, Hain DJ, Zimmerman S. Carlton-LaNey I: identification of potential mediators between depression and fluid adherence in older adults undergoing hemodialysis treatment. Nephrol Nurs J. 2018;45(3):251-8.

13. Cukor D, Rosenthal DS, Jindal RM, Brown CD, Kimmel PL. Depression is an important contributor to low medication adherence in hemodialyzed patients and transplant recipients. Kidney Int. 2009;75(11):1223-9.

14. Little DJ, Ward M, Nee R, Yuan CM, Oliver DK, Abbott KC, Jindal RM. Depression and immunosuppressive therapy adherence following renal transplantation in military healthcare system beneficiaries. Kidney Int Rep. 2017;2(2):248-50.

15. Baines $L S$, Joseph JT, Jindal RM. Prospective randomized study of individual and group psychotherapy versus controls in recipients of renal transplants. Kidney Int. 2004;65(5):1937-42.

16. Thomas Z, Novak M, Platas SGT, Gautier M, Holgin AP, Fox R, Segal M, Looper KJ, Lipman M, Selchen S, Mucsi I, Herrmann N, Rej S. Brief mindfulness meditation for depression and anxiety symptoms in patients undergoing hemodialysis: a pilot feasibility study. Clin J Am Soc Nephrol. 2017;12(12):2008-15 
17. Carnahan JL, Unroe KT, Torke AM. Hospital readmission penalities: coming soon to a nursing home near you! J Am Geriatr Soc. 2016;64(3):614-8.

18. Al-Salmi I, Larkina M, Wang M, Subramanian L, Morgenstern H, Jacobsen SH, Hakim R, Tentori F, Saran R, Akiba T, Tomilina NA, Port FK, Robinson BM,

Pisoni RL. Missed hemodialysis treatments: international variation, predictors, and outcomes in the Dialysis outcomes and practice patterns study (DOPPS). Am J Kidney Dis. 2018;72(5):634-43.

19. Ghimire S, Castelino RL, Jose MD, Zaidi STR. Medication adherence perspectives in hemodialysis patients: a qualitative study. BMC Nephrol. 2017;18(1):167.

20. Rifkin DE, Laws MB, Rao M, Balakrishnan VS, Sarnak MJ, Wilson IB. Medication adherence behavior and priorities among older adults with CKD: a semistructured interview study. Am J Kidney Dis. 2010;56(3):439-46.

21. Griva K, Nandakumar M, Ng JH, Lam KFY, McBain H, Newman SP. Hemodialysis self-management intervention randomized trial (HED_SMART): a practical low-intensity intervention to improve adherence and clinical markers in patients receiving hemodialysis. Am J Kidney Dis. 2017;71(3):371-81.

22. Umuekeye EM, Mixon AS, Cavanaugh KL. Phosphate control adherence in hemodialysis patients: current perspectives. Patient Prefer Adherence. 2018; 12:1175-91.

23. Cakir B, Kaltsounis S, K DJ, Kopf S, Steiner J. Hospital readmissions from patients' perspectives. South Med J. 2017;110(5):353-8.

24. Herzig SJ, Schnipper JL, Doctoroff L, Kim CS, Flanders SA, Robinson EJ, Ruhnke GW, Thomas L, Kripalani S, Lindenauer PK, et al. Physician perspectives on factors contributing to readmissions and potential prevention strategies: a multicenter survey. J Gen Intern Med. 2016; 31(11):1287-93.

25. Bordelon TD. Using DAVE as a model to go beyond treatment compliance with persons receiving renal replacement therapy. Soc Work Health Care. 2002;36(2):35-48.

26. Chan KE, Lazarus JM, Wingard RL, Hakim RM. Association between repeat hospitalization and early intervention in dialysis patients following hospital discharge. Kidney Int. 2009;76(3):331-41.

27. Flythe JE, Katsanos SL, Hu Y, Kshirsagar AV, Falk RJ, Moore CR. Predictors of 30-day hospital readmission among maintenance hemodialysis patients: a hospital's perspective. Clin J Am Soc Nephrol. 2016;11(6):1005-14.

28. Plantinga LC, King LM, Masud T, Shafi T, Burkart JM, Lea JP, Jaar BG. Burden and correlates of readmissions related to pulmonary edema in U.S hemodialysis patients. Nephrol Dial Transplant. 2018;33(7):1215-23.

Ready to submit your research? Choose BMC and benefit from:

- fast, convenient online submission

- thorough peer review by experienced researchers in your field

- rapid publication on acceptance

- support for research data, including large and complex data types

- gold Open Access which fosters wider collaboration and increased citations

- maximum visibility for your research: over $100 \mathrm{M}$ website views per year

At $\mathrm{BMC}$, research is always in progress.

Learn more biomedcentral.com/submissions 